\title{
燃料性状による循環流動層廃棄物混焼特性の予測
}

\section{Prediction of Co-Firing Characteristics of Wastes in Circulating Fluidized Bed by Fuel Properties}

\author{
村上高広* . 須田俊 之*
}

Takahiro MURAKAMI and Toshiyuki SUDA

(Received May 27, 2006)

\begin{abstract}
The purpose of this study is to experimentally investigate the co-firing characteristics of different kinds of wastes in circulating fluidized bed combustors, and further to correlate the acquired combustion efficiency with fuel property parameters. The tested individual fuels were wasted tire, RPF, wood tip, RDF and coal, which typified the fuels with distinctively different contents of volatile matters. Coal was employed to represent the fuel containing particularly low volatile matters. The experiments were carried out in a pilot circulating fluidized bed combustor, and varied parameters included the fuel blending ratio, furnace temperature and secondary air ratio. The acquired results indicated that co-firing wasted tire and RPF led to higher CO concentration in the flue gas than firing RPF independently, and this CO concentration increased with increasing the blending ratio of wasted tire. The lower volatile matter content, higher carbon to hydrogen ratio $(\mathrm{C} / \mathrm{H}$ ratio) and carbon to oxygen ratio $(\mathrm{C} / \mathrm{O}$ ratio) of wasted tire than those of RPF were suggested to be responsible for the results. The study also found that the available combustion efficiencies in co-firing various pairs of the tested fuels were correlative with the volatile matter contents, $\mathrm{C} / \mathrm{H}$ and $\mathrm{C} / \mathrm{O}$ ratios of the blended fuels estimated as the weighed sums of the same property parameters of individual fuels. This allows thus a simple determination of the co-firing efficiency of any fuel blend from calculating the blend's fuel property parameters using the fuel blending ratio as a weight.
\end{abstract}

Key Words: Fluidized Bed, Wastes, Co-Firing, Combustion Efficiency, Fuel Properties

\section{1. 緒言}

近年，廃棄物は増加の一途を辿っており，減容化，資源化 および無害化処理が要求されている。サーマルリサイクルす る手段の一つとして, 流動層然焼ボイラによる発電が挙げら れるが, 廃棄物は多様化しており, その混焼特性を把握して おく必要がある。そこで本研究では, パイロット規模の循環 流動層燃焼試験装置により, 揮発分含有量の異なる燃料を選 択し，その混焼特性を明らかにした。使用した燃料は，廃夕 イヤ, RPF (Refuse Paper \& Plastic Fuel)，木材チップ, RDF (Refuse Derived Fuel) および石炭の 5 種類である。さらに, 燃料性状から混焼特性を予測できるパラメータについて評価 した。

\section{2. 実験装置および方法}

本研究では, パイロット規模の循環流動層燃焼試験装置を 使用した。Fig. 1 に，その概略図を示寸。炉本体は耐火キャ スタブルで成形された内径 $0.36 \mathrm{~m}$, 高さ $15 \mathrm{~m}$ である。流動媒 体は，サイクロン，砂戻り管およびシールポットを経て炉内

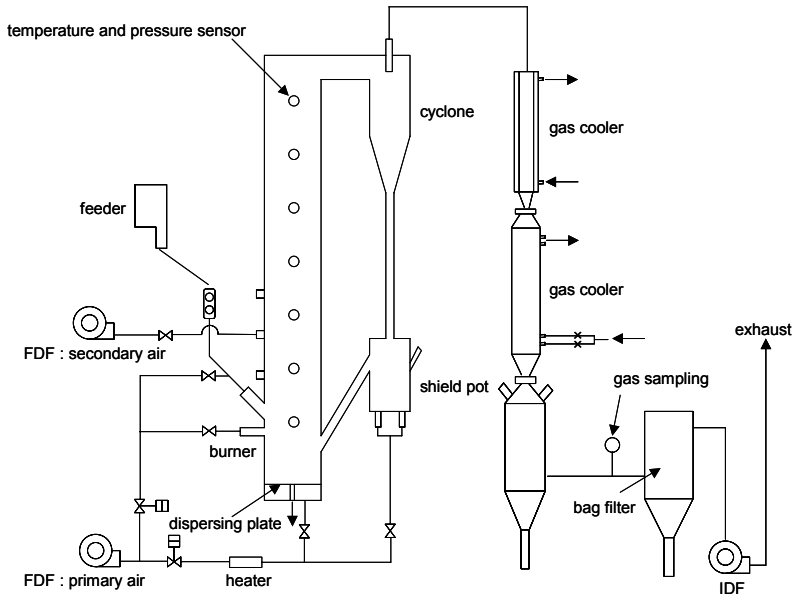

Fig. 1 Schematic of circulating fluidized bed.

一再循環される。排ガスは, 水冷管式の泠却器および水噴霧 式減温塔で泠却され, バグフィルタにより除塵を行う。二次 空気は散気ノズル上 $4.3 \mathrm{~m}$ の位置から供給した。起動は都市 ガスバーナで層温を約 $973 \mathrm{~K}$ まで予熱した後, 燃料を所定の フィーダから供給することで混焼に切り替えた。なお, ベッ

*石川島播磨重工業株式会社(基盤技術研究所) (广235-8501 横浜市磯子区新中原町 1 番地)

Ishikawajima-Harima Heavy Industries Co., Ltd. (1 Shin-Nakahara-cho, Isogo-ku, Yokohama, Kanagawa 235-8501, Japan) 
ド砂は平均粒径が約 $0.3 \mathrm{~mm}$ のものを使用している ${ }^{1), 2)}$

Table 1 に，使用した燃料性状を示す。本研究では，揮発 分の低い燃料についても評価するために石炭を選択した。廃 タイヤは 2 種類のサイズ（1 インチ以下および $150 \mathrm{~mm}$ 角） を使用した。また強化材として，金属ワイヤーを含有してい る。RPF（粒径 : $8 \mathrm{~mm} \phi \times 10 \mathrm{~mm}$ ）は紙や廃プラスチックを, 木材ペレット（粒径 : $5 \mathrm{~mm} \phi \times 10 \mathrm{~mm}$ ) は主に木の皮を, RDF （粒径 : $15 \mathrm{~mm} \phi \times 40 \mathrm{~mm} ）$ は都市ごみをそれぞれ圧縮成型し たものである。石炭は然料比 8.8 の低品位炭を使用した。本 表より，揮発分含有量は，RPF が最も高く，木材チップ， $\mathrm{RDF}$, 廃タイヤ, 石炭の順となっている。石炭の揮発分含有 量は 9.0wt\%であり，他の燃料と比較してかなり低( $\left.{ }^{3)}, 4\right) 。$

Table 2 に, 試験条件を示す。混焼は廃タイヤと RPF, RDF と石炭, 木材チップと RPF との 3 条件実施した。混焼率は, 発熱量ベースで $50: 50$ とした。なお，廃タイヤとRPF 混焼 においては，77：23 および $23: 77$ の混焼率でも実施し，こ の場合の廃タイヤは $150 \mathrm{~mm}$ 角のサイズを使用した。燃焼効 率は，所定時間内に排出する飛灰をバグフィルタで採取し， 採取した灰量とその未燃カーボン濃度から算出した。空気比

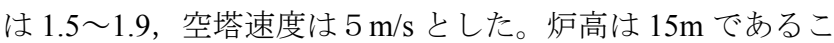
とから, 炉内滞留時間は 3 秒となる。炉内ガス温度は, 1073 〜1173K の範囲で試験を行った。廃タイヤと RPF 混焼にお いては, バイアス率を 18～31\%に変化させた。バイアス率 は, 二次空気量と全空気量 (一次空気量と二次空気量の総量) との割合により算出した。排ガスは $\mathrm{O}_{2}$ および $\mathrm{CO}$ 濃度を測 定した5)。

\section{3. 実験結果および考察}

3. 1 排ガス中の $\mathrm{CO}$ 特性

Fig. 2 に，廃タイヤと RPF 混焼における排ガス中の CO 濃

Table 1 Fuel properties.

\begin{tabular}{|c|c|c|c|c|c|c|}
\hline & & $\begin{array}{l}\text { Wasted } \\
\text { tire }\end{array}$ & RPF & $\begin{array}{l}\text { Wood } \\
\text { tip }\end{array}$ & $\mathrm{RDF}$ & Coal \\
\hline \multirow{4}{*}{$\begin{array}{c}\text { Proximate } \\
\text { analysis } \\
{[\mathrm{wt} \%]}\end{array}$} & Moisture & 0.3 & 3.0 & 6.4 & 4.5 & 2.1 \\
\hline & VM & 62.1 & 84.4 & 78.9 & 74.9 & 9.0 \\
\hline & $\mathrm{FC}$ & 31.1 & 5.4 & 14.1 & 13.2 & 79.5 \\
\hline & Ash & 6.5 & 7.2 & 0.6 & 7.4 & 9.4 \\
\hline \multicolumn{2}{|c|}{ Fuel ratio } & 0.50 & 0.06 & 0.18 & 0.18 & 8.8 \\
\hline \multirow{8}{*}{$\begin{array}{c}\text { Ultimate } \\
\text { analysis } \\
\text { [wt-dry\%] }\end{array}$} & $\mathrm{C}$ & 80.1 & 58.4 & 50.7 & 53.4 & 82.2 \\
\hline & $\mathrm{H}$ & 6.89 & 8.71 & 6.00 & 7.20 & 3.70 \\
\hline & $\mathrm{N}$ & 0.32 & 0.22 & 0.13 & 1.30 & 1.00 \\
\hline & Total S & 1.96 & 0.09 & $<0.01$ & 0.2 & 0.43 \\
\hline & Comb. S & 1.96 & 0.04 & $<0.01$ & 0.2 & 0.34 \\
\hline & $\mathrm{O}$ & 4.23 & 25.23 & 42.57 & 30.5 & 3.30 \\
\hline & $\mathrm{Cl}$ & 0.10 & 0.12 & $<0.01$ & 1.30 & $<0.01$ \\
\hline & $\mathrm{Ca}$ & 0.50 & 0.60 & 0.02 & 1.60 & 0.16 \\
\hline \multicolumn{2}{|c|}{$\begin{array}{c}\text { Heating value (LHV) } \\
{[\mathrm{MJ} / \mathrm{kg}] \text { (dry) }}\end{array}$} & 33.77 & 26.13 & 17.97 & 23.20 & 32.92 \\
\hline
\end{tabular}

Table 2 Experimental conditions.

\begin{tabular}{|c|c|}
\hline Sample & $\begin{array}{l}\text { 1. wasted tire and RPF } \\
\text { 2. RDF and coal } \\
\text { 3. wood tip and RPF }\end{array}$ \\
\hline $\begin{array}{c}\text { Co-firing ratio } \\
\text { (Heating value base) }\end{array}$ & $\begin{array}{l}\text { 1. wasted tire }: \mathrm{RPF}=23: 77,50: 50 \text {, } \\
\text { 2. } \mathrm{RDF}: \mathrm{Coal}=50: 50 \\
\text { 3. wood tip }: \mathrm{RPF}=50: 50\end{array}$ \\
\hline Excess air ratio & $1.5-1.9$ \\
\hline Superficial velocity & $5 \mathrm{~m} / \mathrm{s}$ \\
\hline Residence time in the furnace & $3 \mathrm{sec}$ \\
\hline Gas temperature in furnace & $1073-1173 \mathrm{~K}$ \\
\hline Bias ratio & $\begin{array}{c}18-31 \% \\
\text { (co-firing wasted tire and RPF) }\end{array}$ \\
\hline Exhaust gas analysis & $\mathrm{O}_{2}, \mathrm{CO}$ \\
\hline
\end{tabular}

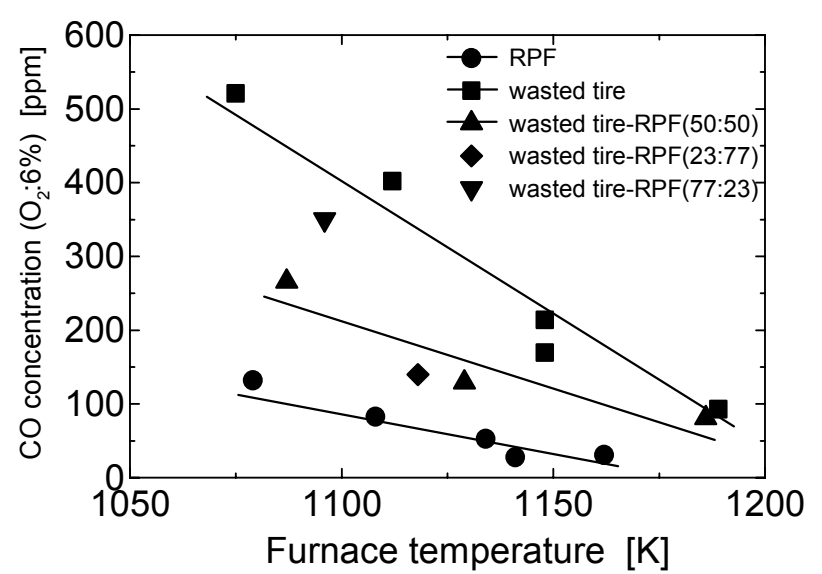

(a) Furnace temperature

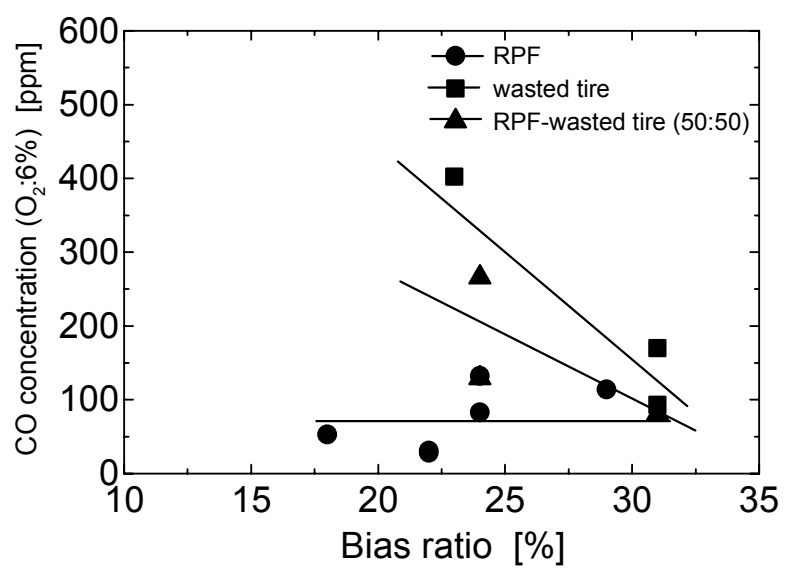

(b) Bias ratio

Fig. 2 CO concentration in exhaust gas for (a) furnace temperature and (b) bias ratio.

度について示す。本図中の(a)は温度，(b)はバイアス率につ いて整理した。本図(a)より, RPF 専焼の場合, CO 濃度は $100 \mathrm{ppm}$ 以下と低いことが分かる。これに対し，廃タイヤ専 焼では, 燃焼温度が $1173 \mathrm{~K}$ 以下では高濃度で排出する傾向 にある。混焼では廃タイヤの混焼率が増加するに連れて, 
CO 濃度も増加していることが分かる。これは Table 1 より， 廃タイヤの方が低揮発分であること, また $\mathrm{C} / \mathrm{H}$ 比で比較す ると, RPF は 6.7 に対し, 廃タイヤは 11.6 と約 1.7 倍高いた めに, $\mathrm{CO}$ 濃度が高くなるといえる。 $\mathrm{C} / \mathrm{O}$ 比の比較からも同 様のことがいえる。本図(b)より, RPF 専焼の場合はバイア ス率の変化に依存しないことが分かる。これに対し, 廃タイ ヤ専焼では，バイアス率 $30 \%$ 以上の条件では CO 濃度は低 下しており，二段然焼の効果があるといえる。以上より， RPF 専焼の場合は炉内温度およびバイアス率を大幅に変化さ せても, 低 CO 燃焼が可能である。これに対し, 廃タイヤ専 焼では, 低 CO 燃焼には炉内温度が $1173 \mathrm{~K}$ 以上でバイアス率 $30 \%$ 以上条件が必要である。例えば，廃タイヤとRDFの ような $\mathrm{Cl}$ 含有量の高い燃料との混焼の際には, ダイオキシ ンの排出が懸念されるが, 本試験条件のようにバイアス率の 高い条件で実施すれば, ある程度対策できるものと推測でき る。さらに, 廃タイヤには硫黄を多く含有しているが, 貝殻 や石灰石のような $\mathrm{Ca}$ 源を脱硫・脱塩剤として炉内一供給す れば，放出量を低減できる実績はある6)。

\section{2 粒径による炉内温度の影響}

Fig. 3 に, 廃タイヤと RPF 混焼における炉内温度分布を示 す。本結果より，1 インチ以下（混焼率 50:50）の廃タイヤ の混焼よりも $150 \mathrm{~mm}$ 角の混焼の方が, 炬内の温度上昇が遅 い。これは, 粒径が大きい, 寸なわち表面積が大きいほど粒 子内に温度分布が生じ, 揮発分放出速度が遅くなることによ る。廃タイヤの混焼率が高くなるに連れて燃料比は高くなる が，150mm 角の混焼がいずれも炉内温度上昇は遅いことか ら, 本温度特性は混焼率よりも粒径に依存する。一方 $5 \mathrm{~m}$ 以 降では, 粒径によらず温度分布の傾向が一致している。本結 果より, Fig. 2 のような炉外で排ガス中の CO 濃度を測定す る場合は, 粒径の影響はないといえる。

\section{3 燃料性状から混焼挙動の予測}

Fig. 4 に，燃焼効率と混焼率との関係を示す。本図中の横 軸の混焼率が大きくなるほど, 廃タイヤあるいは石炭の混焼 率が高くなることを意味している。縦軸は燃焼効率を示して

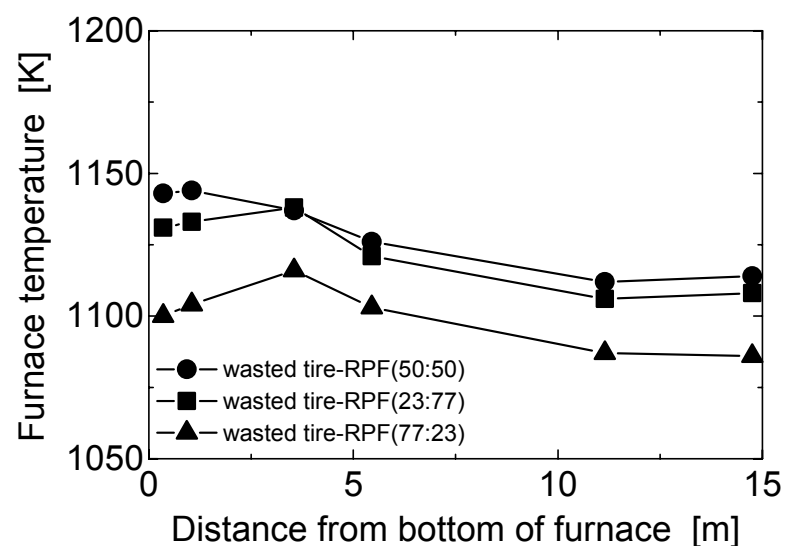

Fig. 3 Furnace temperature distribution for co-firing.
おり, 石炭専焼の燃焼効率を 1 とした場合の各々の条件での それとの割合, すなわち相対的燃焼効率で整理した。結果と して, 廃タイヤあるいは石炭に揮発分含有量の高い RPF や RDF を混合させることにより, 燃焼が促進されている。そ の効果は, 本図中の勾配より, 石炭の方が大きいといえる。

Fig. 5 の(a)は揮発分, (b)は $\mathrm{C} / \mathrm{H}$ 比および(c)は $\mathrm{C} / \mathrm{O}$ 比と燃

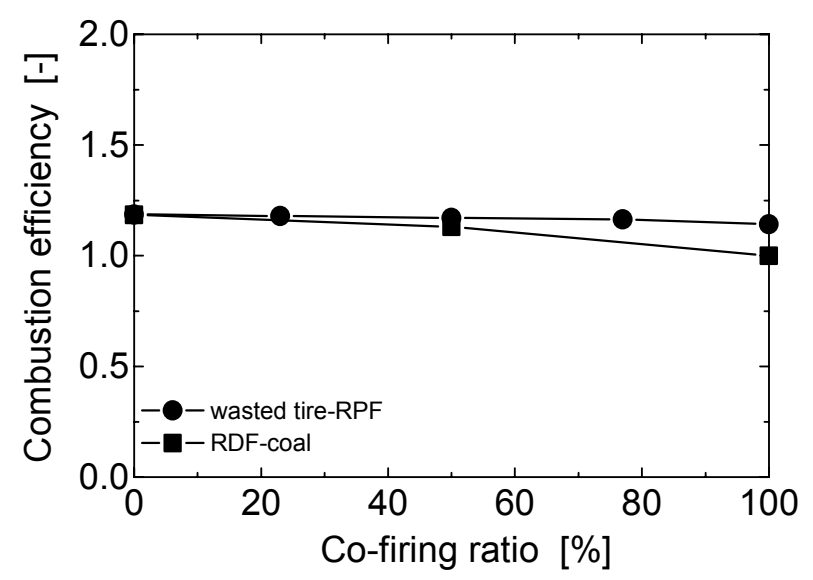

Fig. 4 Relation of combustion efficiency and co-firing ratio.

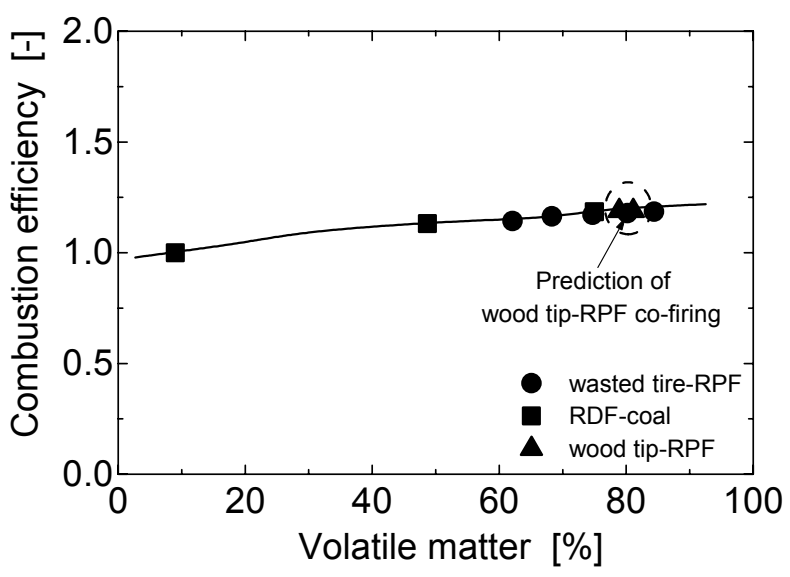

(a) Volatile matter

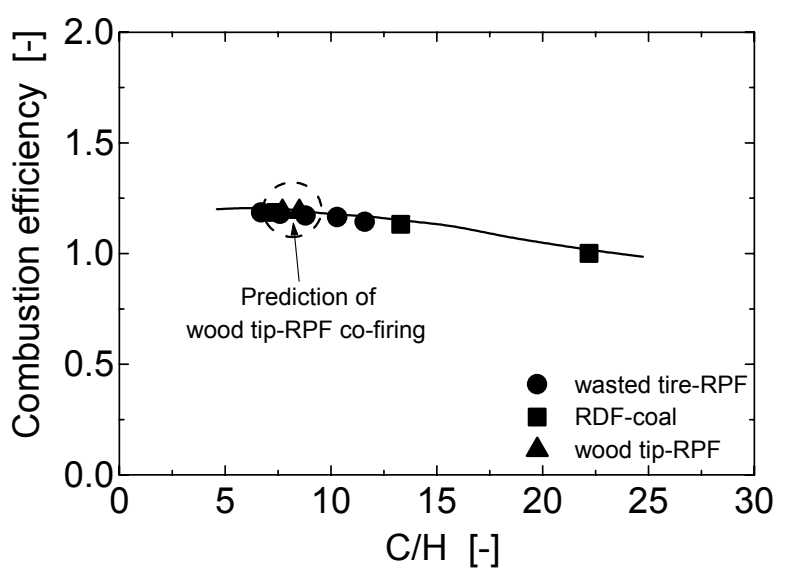

(b) $\mathrm{C} / \mathrm{H}$ ratio 


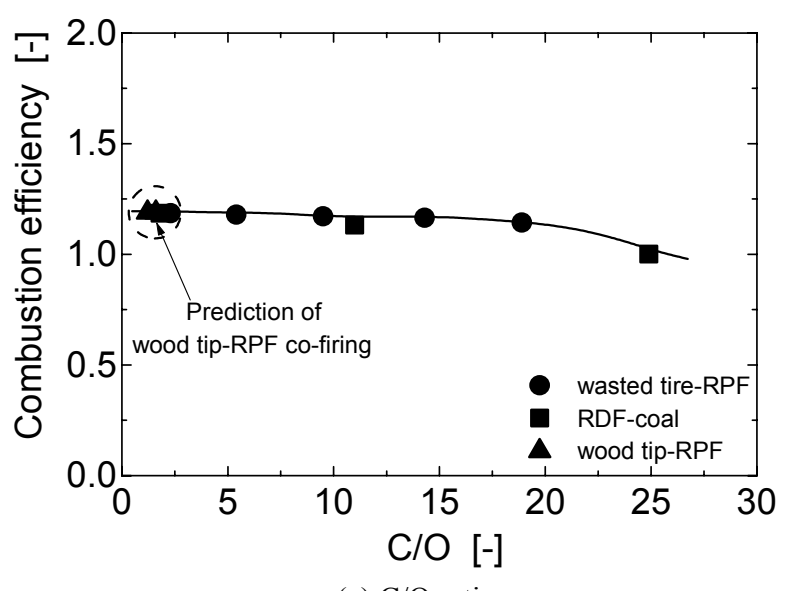

(c) $\mathrm{C} / \mathrm{O}$ ratio

Fig. 5 Predicted index of combustion efficiency for (a) volatile matter, (b) $\mathrm{C} / \mathrm{H}$ ratio and (c) $\mathrm{C} / \mathrm{O}$ ratio.

焼効率との関係をそれぞれ示している。縦軸の燃焼効率は, Fig. 4 の場合々同様に相対的燃焼効率で整理した。本図より, これら 3 種類のパラメータを指標にすれば, 基本的には多種 燃料の専焼および混焼での燃焼効率を整理できる。木材チッ プと RPF 混焼に関しては, 前述した 3 種類の指標により, 図中に示寸ように試験前に結果を予測した。その後, 試験を 実施して燃焼効率を求めた結果, 予測值と一致した。

以上より, 燃料性状中の揮発分, $\mathrm{C} / \mathrm{H}$ 比および $\mathrm{C} / \mathrm{O}$ 比の 3 つの指標により, 循環流動層における多種燃料の燃焼挙動を 予測することができた。これより，試験は代表条件の実施の みで済むため, 新規の燃料種に対しても迅速に評価できるこ とを期待できる。

\section{4. 結言}

パイロット規模の循環流動層燃焼試験装置を使用して, 混 焼率, 炉内温度およびバイアス率をパラメータとして, 多種 廃棄物の燃焼特性を実験的に評価した。得られた結果を以下 に示寸。なお，1) 3)は廃タイヤと RPF 混焼の結果について まとめる。
1）炉内温度を変化させた結果，RPF 専焼の場合， CO は低 濃度であるのに対し, 廃タイヤの混焼率が増加するに連れて $\mathrm{CO}$ 濃度は増加する。これは, 廃タイヤの方が低揮発分であ ること，また $\mathrm{C} / \mathrm{H}$ 比および $\mathrm{C} / \mathrm{O}$ 比が高いことによる。

2） RPF専焼の場合はバイアス率の変化に依存しないのに対 し, 廃タイヤの場合は, バイアス率 $30 \%$ 以上の条件では CO 濃度は低下しており，二段燃焼の効果がある。

3）低 CO 燃焼には，RPF 専焼では炉内温度およびバイアス 率を変化させても問題ない。廃タイヤ専焼では炉内温度が $1173 \mathrm{~K}$ 以上でバイアス率 $30 \%$ 以上の条件が必要である。

4) 粒径が大きいほど粒子内に温度分布が生じ, 揮発分放出 速度が遅くなるため, 炉内の温度上昇が遅くなる。

5) 燃料性状中の揮発分 $(10 \sim 85 \%), \mathrm{C} / \mathrm{H}$ 比 $(5 \sim 25)$ およ び $\mathrm{C} / \mathrm{O}$ 比（2２5）を指標にすれば，基本的には多種燃料の 専焼および混焼での燃焼効率を整理できる。

\section{謝 辞}

本研究には, 株式会社アイテックの浅井稔氏, 石川島検査 計測株式会社の小田幸男氏に, 流動層試験にご協力いただい た。ここに記して，謝意を表する。

\section{引用 文 献}

1) Minoru Asai, Kiyoshi Aoki, Hiromi Shimoda, Keiji Makino, Shuzo Watanabe and Koji Omata: The $3^{\text {rd }}$ Int. Conf. on Circulating Fluidized Beds, (1990) 379-384.

2) Minoru Asai, Kiyoshi Aoki, Yukio Oda and Hiromi Shimoda: The $2^{\text {rd }}$ SCEJ Symp. on Circulating Fluidized Beds, (1988) 101-108.

3) 村上高広, 須田俊之: 第 10 回流動層シンポジウム講演要旨集, (2004) 102-107.

4) Toshiyuki Suda and Takahiro Murakami: The $8^{\text {th }}$ Int. Conf. on Circulating Fluidized Beds, (2005) 559-564.

5) Takahiro Murakami, Toshiyuki Suda and Tetsuya Hirata: FLUIDIZATION 2003 Science and Technology, The $8^{\text {th }}$ China-Japan Symposium, (2003) 360-365.

6) 村上高広, 劉志宏, 平田哲也, 綾部統夫, 黄偉光 : 高温学会誌, (2006) 179-183. 